\title{
Lumbar epidural abscess caused by brucella species: report of two cases
}

\author{
E. Daglioglu; N. Bayazit*; O. Okay; A. Dalgic; H.G. Hatipoglu** and F. Ergungor
}

Neurosurgery clinics. *Department of Infectious Diseases and Clinical Microbiology. **Department of Radiology. Ankara Numune Education and Research Hospital. Ankara. Turkey

\section{Summary}

Spinal epidural abscess due to Brucella species is usually associated with spondylodiscitis. Urgent surgical decompression should be performed in cases with moderate to severe neurological deficits particularly if progressive. We report clinical features of two cases operated for lumbar epidural abscess caused by Brucella species. Early surgical decompression combined with medical treatment could decrease progression of neurological findings or the severity of complications. Iatrogenic dural tear at the operation should be repaired immediately with fine sutures and fibrin tissue glue to prevent further innoculation into the cerebrospinal axis. These cases should be cautiously followed for any recurrence or neurobrucellosis.

KEY WORDS: Epidural abscess. Brucellosis. Brucella spondylitis. Lumbar region. Surgery. Dural tear

Absceso epidural lumbar causado por brucella: descripción de dos casos

\section{Resumen}

Los abscesos epidurales espinales debidos a Brucella se asocian habitualmente a espondilodiscitis. La descompresión quirúrgica urgente debe ser realizada en casos con déficit neurológico moderado o grave particularmente si este es progresivo. Describimos los aspectos clínicos de dos casos operados por abscesos epidurales causados por Brucella. El tratamiento quirúrgico temprano asociado con tratamiento médico puede disminuir la progresión de la sintomatología neurológica y la gravedad de las complicaciones. La aparición de desgarros durales durante la cirugía debe ser reparada de forma inmediata con sutura o pegamentos de fibrina para prevenir la inoculación dentro del neuroeje. Estos casos deben ser seguidos de forma

Recibido: 3-04-08. Aceptado: 30-09-08 cuidadosa para evitar la recurrencia de la neurobrucelosis.

PALABRAS CLAVE: Absceso epidural. Brucelosis. Espondilitis por brucella. Región lumbar. Cirugía. Desgarro dural.

\section{Introduction}

Brucella species are intracellular slow-growing gram negative bacilli giving rise to an indolent infection usually with mild symptoms. Spondylitis due to Brucella species is more prevalent in endemic areas and neurological involvement is rare ${ }^{1,5,15}$. Definitive diagnosis of vertebral involvement depends on profound suspicion due to insidious onset of these infections. Initial diagnosis could be malignancy, degenerative conditions or other infectious agents. Spinal epidural abscess is a rare complication in the course of spondylitis caused by Brucella species. The incidence of spondylitis in Brucellar infection is about $10 \%$, however, development of spinal epidural abscess is $\operatorname{rare}^{1,5,7,8,11,15}$. Lumbar vertebrae are the most common region for epidural abscesses whereas involvement of the cervical spinal cord is uncommon. Prompt surgical treatment should be performed particularly in cases with severe neurological deficits ${ }^{4,12,15}$. There is a significant risk of sudden neurological deterioration in cases managed conservatively. Here we report two cases of lumbar epidural abscesses due to Brucella species which were managed with radical surgical measures and followed for any possible recurrence or neurobrucellosis.

\section{Report of two cases}

\section{Case 1}

A 34-year-old man presented with lumbalgia and pain on left leg for the last three months. Generalized fatique, myalgia, mild sweating and fever at night were the other complaints. Physical examination was normal and neurological examination revealed mild weakness $(4 / 5)$ and 


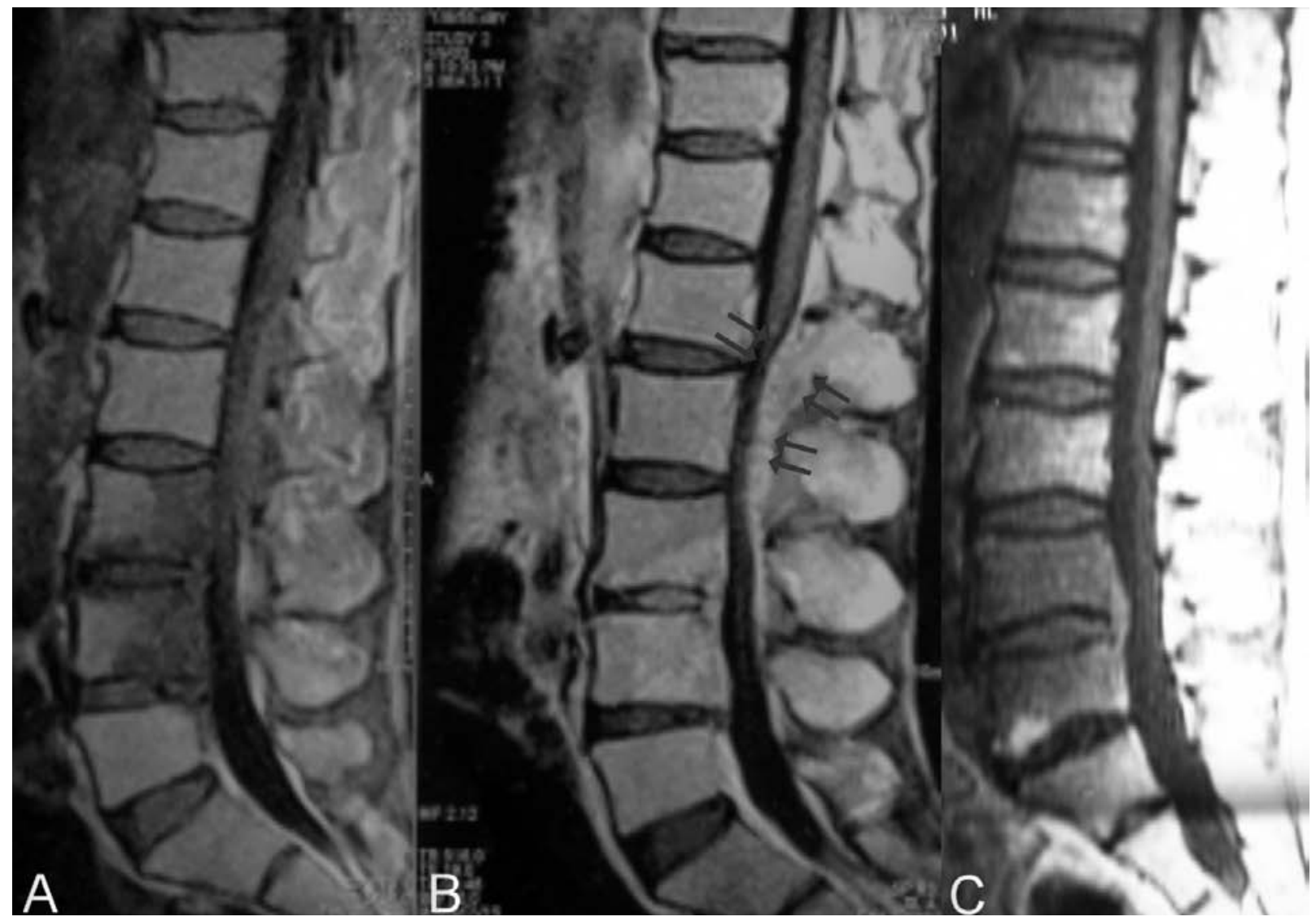

Figure 1. A. Sagittal T1-weighted MR images of the lumbosacral region shows hypointense changes on L3 and L4 corpus and slightly hyperintense lesion posterior to the L1 and L2 vertebrae. B. Marked gadolinium enhancement and mass effect of the lesion posterior to the thecal sac. C. Postoperative sagittal lumbar image demonstrating complete removal.

increased muscle tonus on both lower extremities with increased deep tendon reflexes. Lumbar MRI demonstrated an epidural mass posterior to the dural sac at L1 and L2 levels (Figure 1A and 1B). Titer of antibodies to Brucella species was measured as 1/640 and CRP level was 105. At the operation, epidural mass was removed via L1 and L2 laminectomies. The mass was noted to be tightly adherent to the dural sac without any invasion. Histopathological examination of this epidural lesion was found to be compatible with spinal brucella abscess. Postoperative course was uneventful and the patient was discharged 9 days after the operation. He was treated with intramuscular streptomisin 1 gr per day for 21 days, and oral rifampicin $600 \mathrm{mg}$ per day and oral doxycycline $100 \mathrm{mg}$ twice a day for 8 months. The patient was symptom free without any recurrence of clinical and radiological findings after 4 years (Figure 1C).

\section{Case 2}

A 53-year-old woman was admitted with complaints of lumbalgia, pain and numbness in left leg. She was a living in a farm and had a direct contact with cows and milk pro- ducts. She also had complaints of night fever and arthralgia. Neurological examination showed motor weakness on distal parts of both lower extremities. She was presumed to have lumbar disc herniation and lumbar MRI revealed a spinal epidural mass anterior to dural sac at L5 and S1 levels (Figure 2A and 2B). The lesion was $4 X 5 X 1.5 \mathrm{~cm}$ in size and showed heterogeneous contrast enhancement. Standard tube agglutination testing revealed a titer of antibodies to Brucella of 1/1280. CRP was found to be 140 . There was no growth in blood culture. At the operation, L4 inferior and L5 total laminectomies were performed via posterior approach. L4, L5 and S1 nerve roots were decompressed bilaterally during the removal of the mass. Dural sac was torn iatrogenically at L5 level on the left side and repaired immediately with sutures and fibrin glue. The mass was elastic, moderately vascular and tightly attached to the dural sac, and also involved L5-S1 disc interspace. The mass was removed grossly as total leaving some portions of the capsule. She was treated with intramuscular streptomisin 1 gr per day for 21 days, and oral rifampicin $600 \mathrm{mg}$ per day and oral doxycycline $100 \mathrm{mg}$ twice a day for 6 months. She was symptom free with a normal neuro- 


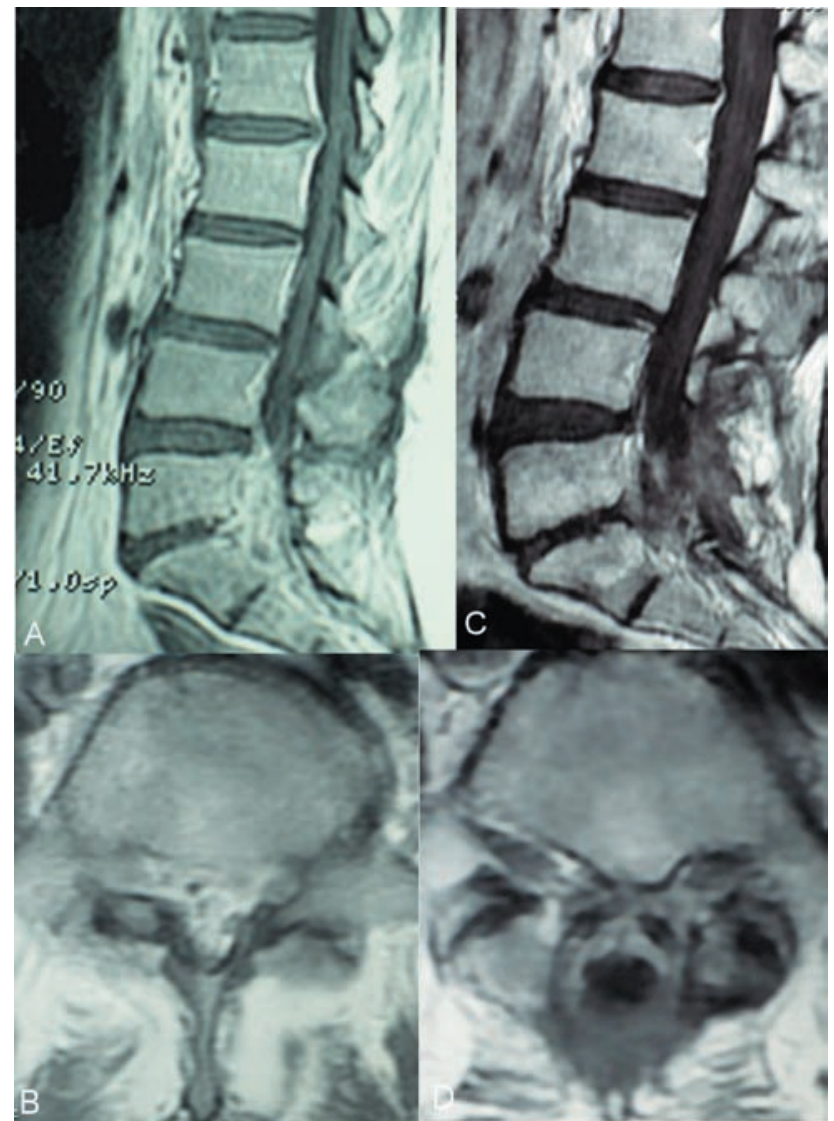

Figure 2. A. Sagittal T1-weighted MR images with contrast demonstrated marked heterogeneous contrast enhancement of the lesion posterior to the L5 and S1 vertebra. B. The lesion fills up almost the whole spinal with marked heterogeneous gadolinium enhancement on axial T1-weighted MR images. C. Postoperative contrast enhanced sagittal MR images after 18 months show mild capsular enhancement and postoperative changes. D. Axial T1-weighted MR image shows mild gadolinium enhancement around thecal sac and significant decompression.

logical examination and laboratory studies at 6 months of follow-up, and neuroradiological studies revealed a small residual contrast enhanced tissue, which resolved completely at 21 months of follow-up (Figure $2 \mathrm{c}$ and $2 \mathrm{~d}$ ).

\section{Discussion}

Brucella species give rise to a slow growing infection usually with mild symptoms. The disease is usually encountered in the rural areas and in the people who consume unpasteurized diary products. Spinal epidural abscess is one of the morbidities caused by brucellosis and surgical intervention should be performed immediately.

A high index of suspicion is necessary in the diagnosis,
2009 20: 159-162

especially in the endemic areas of brucellosis. The diagnosis is disclosed with history, physical examination, blood tests for brucellosis, and radiological and histopathological means ${ }^{8}$. Positive blood culture is a definite diagnostic tool however proper use of culture techniques, preparation of several specimens and proper timing of culture particularly before administration of antibiotic treatment are the key features increasing the frequency of growth in culture ${ }^{3,10,13}$. Furthermore, culture of surgical or biopsy specimens could give another chance to reveal the presence of Brucella species. In both cases, although Brucella species could not be cultivated from the blood, the other diagnostic options like history, physical examination, radiological and histopathological findings, standard tube agglutination (Wright test results with titers $>$ or $=1 / 160$ ) and high CRP value were consistent with brucellosis. In the follow up period after medical and surgical treatments, both patients were symptom free, and their CRP levels were all within normal limits.

Spinal epidural abscesses should be treated immediately since prompt surgical intervention can prevent or decrease the severity of complications ${ }^{12,15}$. Combination of both medical and surgical treatments is necessary to alleviate the disease ${ }^{16}$. However, conservative treatment with close observation may be sufficient in selected cases, particularly in the elderly ${ }^{6}$.

Severe neurological deficits are usually associated with cervical epidural abscesses due to Brucella infections ${ }^{8}$. Brucella infections can also mimic findings of lumbar disc herniation or sciatic pain ${ }^{7,12}$. In the present report, cases present with mild to moderate findings of neural compression. Although recovery is noted to be partial in cases with severe neurological deficits, there is a chance of significant improvement or cure in cases with moderate neurological manifestations ${ }^{1,7}$.

Immediate surgical intervention can decrease or eliminate morbidity in cases with spinal epidural abscess. Spinal abscess due to Brucella species should be treated both medically and surgically especially when neuroradiological images point to a severe mass effect on the neural structures. However, medical treatment could be an alternative to surgery in benign soft-tissue lesions in the absence of neurological deterioration ${ }^{3,13}$. Imaging studies for Brucella spondylitis do not give clues about definitive diagnosis ${ }^{3,12}$. Biopsy or surgical intervention is indicated to rule out other granulomatous lesions like tuberculosis when the diagnosis is indefinite despite neuroradiological and clinical stu$\operatorname{dies}^{9,12}$.

Surgery could be palliative or directed to the reduction of mass effect in lesions adherent to critical neural elements. Lesions induced by these slow-growing organisms are usually encapsulated, elastic in nature and firmly adherent to neural structures therefore complicating the dissection 
from neural elements. These lesions are also moderately vascular which makes the surgery quite challenging. Peroperative cerebrospinal fluid leak is an unexpected and fearful complication during the surgical procedure for spinal epidural abscess due to Brucella infection. Although spread of Brucella is due to consumption of raw milk, local inoculation with direct contact is possible ${ }^{11-14}$. Iatrogenic inoculation of organism into the cerebrospinal fluid could induce distant innoculations. However immediate repair of dural tear with fine sutures and use of fibrin glue together with fascia grafts could prevent this unpredicted complication as reported in Case 2.

Long-term medical treatment is necessary as brucellosis gives rise to low grade infections. Treatment can be prolonged to 6 to 12 months in cases with residual perineural abscesses $^{2}$. Neuroradiological follow-up with periodical MR studies is beneficial for the decision about the duration of medical treatment.

In conclusion, although rare, epidural abscess due to brucellosis should be remembered in the differential diagnosis of the spinal cord lesions particularly in the endemic areas.

\section{References}

1. Ates, O., Cayli, S.R., Koçak, A., Kutlu, R., Onal, R.E., Tekiner, A.: Spinal epidural abscess caused by brucellosis. Two case reports. Neurol Med Chir (Tokyo) 2005; 45: 66-70.

2. Bodur, H., Erbay, A., Colpan, A., Akinci, E.: Brucellar spondylitis. Rheumatol Int 2004; 24: 221-226.

3. Colmenero, J.D., Jiménez-Mejías, M.E., Sánchez-Lora, F.J., Reguera, J.M., Palomino-Nicás, J., Martos, F., García de las Heras, J., Pachón, J.: Pyogenic, tuberculous, and brucellar vertebral osteomyelitis: a descriptive and comparative study of 219 cases. Ann Rheum Dis 1997; 56: 709-715.

4. Coskun, E., Suzer, T., Yalcin, N., Tahta, K.: Spinal extradural compression caused by granuloma of brucellosis. Scand J Infect Dis 1998; 30: 311-313.

5. Görgülü, A., Albayrak, B.S., Görgülü, E., Tural, O., Karaaslan, T., Oyar, O., Yilmaz M.: Spinal epidural abscess due to Brucella. Surg Neurol. 2006; 66: 141-147.

6. Güzey, F.K., Emel, E., Sel, B., Bas N.S., Ozkan, N., Karabulut, C., Solak, O., Esenyel, M.: Cervical spinal brucellosis causing epidural and prevertebral abscesses and spinal cord compression: a case report. Spine J. 2007; 7: 240-244.
7. Izci, Y.: Lumbosacral spinal epidural abscess caused by Brucella melitensis. Acta Neurochir (Wien) 2005; 147: $1207-$ 1209.

8. Pina, M.A., Modrego, P.J., Uroz, J.J., Cobeta, J.C., Lerin, F.J., Baiges, J.J.: Brucellar spinal epidural abscess of cervical location: report of four cases. Eur Neurol 2001; 45: 249-253.

9. Sharif, H.S., Aideyan, O.A., Clark, D.C., Madkour, M.M., Aabed, M.Y., Mattsson, T.A., al-Deeb, S.M., Moutaery, K.R.:: Brucellar and tuberculous spondylitis: comparative imaging features. Radiology 1989; 171: 419-425.

10. Solera, J., Rodríguez-Zapata, M., Geijo, P., Largo, J., Paulino, J., Sáez, L., Martínez-Alfaro, E., Sánchez, L., Sepulveda, M.A., Ruiz-Ribó M.D.: Doxycycline-rifampin versus doxycycline-streptomycin in treatment of human brucellosis due to Brucella melitensis. Antimicrob Agents Chemother 1995; 39: 2061-2067.

11. Solera, J., Lozano, E., Martínez-Alfaro, E., Espinosa, A., Castillejos, M.L., Abad, L.: Brucellar spondylitis: review of 35 cases and literature survey. Clin Infect Dis 1999; 29: 1440-1449.

12. Stabler, A., Reiser, M.F.: Imaging of spinal infection. Radiologic Clinics of North America 2001; 39: 115-135.

13. Tekkok, I.H., Berker, M., Ozcan, O.E., Ozgen, T., Akalin, E.: Brucellosis of the spine. Neurosurgery 1993; 33: 838-844.

14. Trujillo, I.Z., Zavala, A.N., Caceres, J.G., Miranda, C.Q.: Brucellosis. Infect Dis Clin North Am 1994; 8: 225241.

15. Ugarriza, L.F., Porras, L.F., Lorenzana, L.M., Rodríguez-Sánchez, J.A., García-Yagüe, L.M., Cabezudo, J.M.: Brucellar spinal epidural abscesses. Analysis of eleven cases. Br J Neurosurg 2005; 19: 235-240.

16. Yuksel, K.Z., Senoglu, M., Yuksel, M., Gul, M.: Brucellar spondylo-discitis with rapidly progressive spinal epidural abscess presenting with sciatica. Spinal Cord 2006; 44: 805808.

Daglioglu, E.; Bayazit, N.; Okay, O.; Dalgic, A.; Hatipoglu, H.G.; Ergungor, F.: Lumbar epidural absces caused by brucella species: report of two cases. Neurocirugía 2009; 20: $159-162$.

Address of correspondance: Ergun Daglioglu, Kuzgun Sokak, 15/14, Asagiayranci 06540, Ankara, Turkey 